\title{
Nanostructured Energetic Materials Using Sol-Gel Methodologies
}

T. M. Tillotson, R. L. Simpson, L. W. Hrubesh, A. E. Gash, I. M. Thomas, J. F. Poco

This article was submitted to International Symposium on Aerogels, Albuquerque, NM., October 8-11, 2000

\section{September 27, 2000}

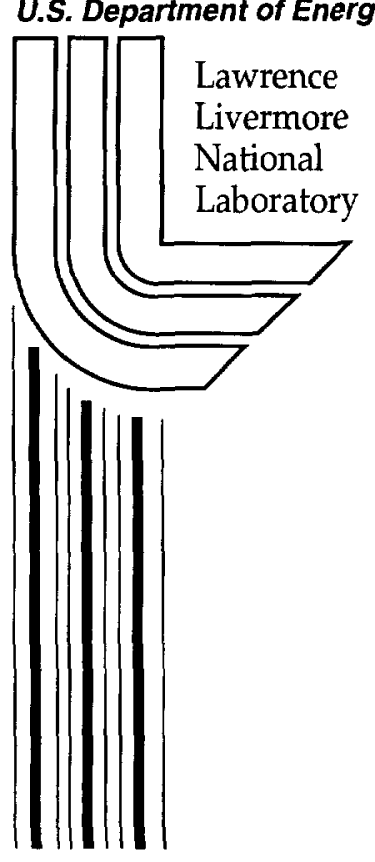




\section{DISCLAIMER}

This document was prepared as an account of work sponsored by an agency of the United States Government. Neither the United States Government nor the University of California nor any of their employees, makes any warranty, express or implied, or assumes any legal liability or responsibility for the accuracy, completeness, or usefulness of any information, apparatus, product, or process disclosed, or represents that its use would not infringe privately owned rights. Reference herein to any specific commercial product, process, or service by trade name, trademark, manufacturer, or otherwise, does not necessarily constitute or imply its endorsement, recommendation, or favoring by the United States Government or the University of California. The views and opinions of authors expressed herein do not necessarily state or reflect those of the United States Government or the University of California, and shall not be used for advertising or product endorsement purposes.

This is a preprint of a paper intended for publication in a journal or proceedings. Since changes may be made before publication, this preprint is made available with the understanding that it will not be cited or reproduced without the permission of the author.

This work was performed under the auspices of the United States Department of Energy by the University of California, Lawrence Livermore National Laboratory under contract No. W-7405-Eng-48.

This report has been reproduced directly from the best available copy.

Available electronically at http://www.doc.gov/bridge

Available for a processing fee to U.S. Department of Energy

And its contractors in paper from

U.S. Department of Energy

Office of Scientific and Technical Information

P.O. Box 62

Oak Ridge, TN 37831-0062

Telephone: (865) 576-8401

Facsimile: (865) 576-5728

E-mail: reports@adonis.osti.gov

Available for the sale to the public from

U.S. Department of Commerce

National Technical Information Service

5285 Port Royal Road

Springfield, VA 22161

Telephone: (800) 553-6847

Facsimile: (703) 605-6900

E-mail: orders@ntis.fedworld.gov

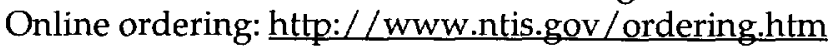

\section{OR}

Lawrence Livermore National Laboratory

Technical Information Department's Digital Library

http://www.llnl.gov/tid/Library.html 


\title{
Nanostructured energetic materials using sol-gel methodologies
}

T.M. Tillotson, R.L. Simpson, L.W. Hrubesh, A.E. Gash, I.M. Thomas, \& J.F. Poco

\begin{abstract}
The fundamental differences between energetic composites and energetic materials made from a monomolecular approach are the energy density attainable and the energy release rates. For the past 4 years, we have been exploiting sol-gel chemistry as a route to process energetic materials on a microstructural scale. At the last ISA conference, we described four specific sol-gel approaches to fabricating energetic materials and presented our early work and results on two methods - solution crystallization and powder addition. Here, we detail our work on a third approach, energetic nanocomposites. Synthesis of thermitic types of energetic nanocomposites are presented using transition and main group metal-oxide skeletons. Results on characterization of structure and performance will also be given.
\end{abstract}

\section{Introduction}

Initiation and detonation properties of energetic materials are strongly influenced by their microstructural properties. Our main interest here in the sol-gel approach to energetic material processing was that it offers the possibility to achieve precise control of oxidizer-fuel balance, intimately mixed on the nanometer scale; a result that is difficult or not possible by most conventional procedures.

Energetic materials are substances that store energy chemically and are typically categorized as propellants, explosives, and pyrotechnics. Since the invention of black powder, over a thousand years ago, the technology for making solid energetic materials has remained largely unchanged. Their preparation involves either the physical mixing of solid oxidizers and fuels (e.g. black powder) to produce a composite, or the incorporation of oxidizing and fuel moieties into one molecule (e.g. trinitrotoluene, TNT) to form a monomolecular energetic material. 
The basic distinctions between the composite and monomolecular approaches to obtain energetic materials are as follows. In composite systems, desired energy properties can be attained through readily varied ratios of oxidizer and fuels. A complete balance between the oxidizer and fuel may be reached to maximize energy density. However, due to the granular nature of composite energetic materials, reaction kinetics are mainly controlled by the mass transport rates between reactants. Although composites may have extreme energy densities, the release rate of that energy is below that which may be attained in a chemical kinetic controlled process, i.e., a monomolecular energetic material.

In previous accounts, we described four specific sol-gel approaches for preparing energetic materials [1] and presented early results on two methods - solution crystallization and powder addition [2]. Here, we detail our work on the nanocomposite approach. Nanocomposites are multicomponent materials in which at least one of the component phases has one or more dimensions (length, width, or thickness) in the nanometer size range, usually defined as 1 to $100 \mathrm{~nm}$. Energetic nanocomposites are defined as a material that has a fuel component and an oxidizer component intimately mixed on the nanometer scale. An example would be an organic skeletal matrix acting as a fuel, with an oxidizer embedded within this network. Work detailing a resorcinol/formaldehyde - ammonium perchlorate system that meets the criteria was recently described [2].

Conversely, one can make an oxidizing network with a fuel residing within its structure. We have made metal-oxide-based pyrotechnics where the network is synthesized by sol-gel chemistry and metal fuel particles are embedded within the skeletal porosity. It should be noted that both the network (oxidizer) and fuel need not be single components. In fact, varying the composition of either phase is used to tailor the properties of the energetic material. The generalized reaction can be written as:

$$
\mathrm{M}_{(1)}+\mathrm{M}_{(2)} \mathrm{O} \rightarrow \mathrm{M}_{(1)} \mathrm{O}+\mathrm{M}_{(2)}+\Delta H
$$

where $\mathrm{M}_{(1)}$ is a metal and $\mathrm{M}_{(2)}$ is the oxide of a different metal and $\Delta H$ is the heat of reaction. Thermites are most widely used in the field-welding process for rails [3] but are finding applications in the synthesis of refractory ceramic and composite materials [4-6], 
as experimental models for solid combustion studies [7-9], as cost-effective methods for storing radioactive waste [10], and for pyrotechnic uses [11,12].

\section{Experimental}

\subsection{Oxidizing-skeleton / fuel nanocomposites}

In an earlier account, we described a sol-gel procedure for synthesizing lanthanide oxide aerogels from hydrated salts of erbium, praesodymium, and neodymium using propylene oxide as a gelating agent [13]. This synthesis approach works well for a variety of inorganic metal oxides, and we have used it successfully to make an iron-oxide oxidizing skeleton from Fe(III) salts for a nanocomposite thermite. The details and mechanism of this synthesis including the dependence of gel formation and rate on the type of epoxide used, epoxide/Fe(III) ratio, amount of water present $\left(\mathrm{Fe} / \mathrm{H}_{2} \mathrm{O}\right)$, along with the preferred solvent choice (i.e., polar vs. non-polar, aprotic vs. protic) has been previously described in detail [14]. Essentially, with a sufficient amount of water and epoxide, preferably in a polar protic solvent, the formation of transparent red-brown monolithic gels can rapidly form. It should be noted that the epoxide acts as a gelating agent that is consumed in the process of gel formation and not as a catalyst.

In a typical procedure, $1.0 \mathrm{~g} \mathrm{Fe}\left(\mathrm{NO}_{3}\right)_{3} \cdot 9 \mathrm{H}_{2} \mathrm{O}(2.5 \mathrm{mmol})$ is dissolved in $5.0 \mathrm{~g}$ of 200 proof ethanol with stirring to give a clear red-orange solution. Upon the addition of $1.0 \mathrm{~g}$ propylene oxide $(17 \mathrm{mmol})$, there is a rapid exothermic reaction accompanied by a color change to a dark red-brown solution. Gelation occurs in less than 5 minutes. Powdered metal fuels, like aluminum, are added just before gelation to obtain the best homogeneity. As above, the final step of removing the pore fluid is done by either a slow evaporation or by supercritical extraction (SCE) with carbon dioxide.

\subsection{Binary oxidizing-skeleton / fuel nanocomposites}

By modifying a two-step sol-gel procedure that we first developed in the early 1990s for preparing ultralow density silica aerogels [15], we have synthesized other thermite nanocomposites with binary iron-silicate oxidizing skeletons and a powdered aluminum fuel. In the first step, a sub-stoichiometric amount of water is added to 
tetramethoxysilane (TMOS) and allowed to react. Hydrated iron (III) nitrate $\left(\mathrm{Fe}\left(\mathrm{NO}_{3}\right)_{3} \bullet 9 \mathrm{H}_{2} \mathrm{O}\right)$ is added to the solution at this stage, and a small amount of acid is added to promote some hydrolysis reactions while also slowing the condensation reactions. The molar amount of water used is kept to less than 1.6 moles water per mole of TMOS, including the water from the hydrated salt. In the second step, the additional water needed to complete the hydrolysis, and a fluoroboric acid catalyst, are added to the solution. As in the example above, with a pre-determined gel time, powdered aluminum is added just prior to gelation. Again as in the examples above, the final step of removing the pore fluid is done by either a slow evaporation or by SCE with carbon dioxide

\subsection{Physical characterization}

High resolution transmission electron microscopy (HRTEM) was performed on a Philips CM300FEG operating at $300 \mathrm{KeV}$ using zero loss energy filtering with a Gatan energy Imaging Filter (GIF) to remove inelastic scattering. The images where taken under BF (bright field) conditions and slightly defocused to increase contrast. The images were recorded on a $2 \mathrm{~K} \times 2 \mathrm{~K}$ CCD camera attached to the GIF.

Surface area and pore volume and size analyses were performed by BET (Brunauer-Emmett-Teller) and BJH (Barrett-Joyner-Halenda) methods using an ASAP 2000 Surface area Analyzer (Micromeritics Instrument Corporation). Samples of approximately $0.1-0.2 \mathrm{~g}$ were heated to $200^{\circ} \mathrm{C}$ under vacuum $\left(10^{-5}\right.$ Torr $)$ for at least 24 hours to remove all adsorbed species. Nitrogen adsorption data was taken at five relative pressures from 0.05 to 0.20 at $77 \mathrm{~K}$, to calculate the surface area by BET theory.

Scattering data were collected on a $30 \mathrm{~m}$ small-angle neutron scattering spectrometer (SANS) at the National Institute of Standards and Technology in Gaithersburg, MD. A neutron wavelength of $0.6 \mathrm{~nm}$ and three sample-to-detector distances were used to cover a momentum transfer range of $0.04 \mathrm{~nm}^{-1}$ to $5.0 \mathrm{~nm}^{-1}$. Contrast-matching SANS, a technique for independently characterizing the structures of two-phase nanocomposites, was performed on the binary oxidizing skeletons (minus the fuel component).

\section{Results}


The sol-gel procedures for preparing energetic nanocomposites described here resulted in nanostructured skeletons and, as such, satisfy the accepted nanocomposite definition. Data obtained for both compositions of energetic nanocomposites is detailed below.

HRTEM (Fig. 1a) of an iron-oxide/aluminum thermite nanocomposite xerogel shows an interconnected iron-oxide solid skeleton with cluster sizes considerably smaller, about one order of magnitude, than the $30 \mathrm{~nm}$ aluminum fuel particles. The fuel particles tended to aggregate but intimate mixing of the oxidizing skeleton is still observed and we anticipate better homogeneity as we improve our control of gel time and mixing of fuel prior to gelation. The highlighted aluminum particle in figure 1a clearly has an oxide coating, as expected, but the bulk of the particle is aluminum, which was confirmed by its X-ray diffraction pattern (Fig. 1b.).
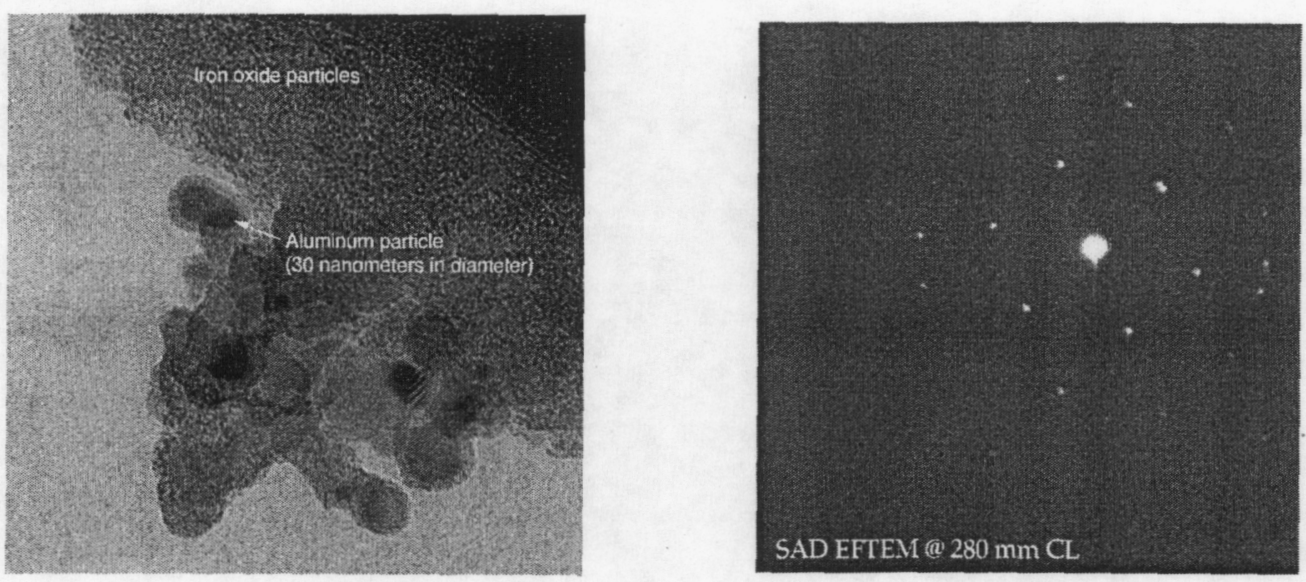

Figure1. TEM of a $\mathrm{Fe}_{x} \mathrm{O}_{y}-\mathrm{Al}$ energetic nanocomposite and the $x$-ray diffraction pattern comfirming that the fuel is metallic aluminum.

HRTEMs for iron-oxide and binary iron-oxide silicate aerogels (minus the fuel component) showed the typical interconnected bead-like structure. BET surface areas for the oxidizing skeletons are given in Table 1. The iron oxide values ranged from 300 to $390 \mathrm{~m}^{2} / \mathrm{g}$ depending on the precursor salt used in the synthesis, while the iron oxidesilicate had a slightly higher value of $578 \mathrm{~m}^{2} / \mathrm{g}$. This higher value is attributed to the contribution of the network silicate and should vary according to the weight percent of each component in the composite. 
Table 1. Summary of $\mathrm{N}_{2}$ adsorption/desorption results for dry $\mathrm{Fe}_{2} \mathrm{O}_{3}$ and $\mathrm{Fe}_{2} \mathrm{O}_{3} \cdot \mathrm{SiO}_{2}$.

\begin{tabular}{lcccc}
\hline $\begin{array}{c}\text { Gel } \\
\text { Type }\end{array}$ & $\begin{array}{c}\text { Composition } \\
\text { Surface Area }\end{array}$ & $\begin{array}{c}\text { Pore Vol. } \\
(\text { BET })\left(\mathrm{m}^{2} / \mathrm{g}\right)\end{array}$ & $\begin{array}{c}\text { Ave. Pore } \\
(\mathrm{m} / \mathrm{g})\end{array}$ & $\begin{array}{c}\text { Diameter }(\mathrm{nm}) \\
\text { Xerogel }\end{array}$ \\
$\mathrm{Fe}_{2} \mathrm{O}_{3}$ & 300 & 0.22 & 2.6 \\
Aerogel & $\mathrm{Fe}_{2} \mathrm{O}_{3}$ & 340 & 1.25 & 12 \\
Aerogel & $\mathrm{Fe}_{2} \mathrm{O}_{3} \cdot \mathrm{SiO}_{2}$ & 578 & .34 & 26 \\
\hline
\end{tabular}

A variant of SANS involving a phase-contrast technique, was used to characterize the binary oxidizing skeletons. Phase-contrast SANS is a non-destructive method for determining how one phase in a nanostructure is dispersed within the other. It has been used extensively in the field of ceramics and has recently been used as a characterization tool for the nanostructure of aerogels, by Merzbacher and co-workers [16,17]. In this method, a mixture of $\mathrm{D}_{2} \mathrm{O} / \mathrm{H}_{2} \mathrm{O}$ is wicked into the skeleton to match the neutron crosssection for one of the phases, essentially hiding the structure of that phase while elucidating the structure of the other. The results for the iron-silicate sample identified an iron-oxide nanostructure that is similar to the typical silicon-oxide structure (see Fig. 2). The iron-oxide skeleton, however, showed primary particles which are slightly larger in size than the primary particles of the silica skeleton. Unfortunately, the technique was unable to conclusively determine whether the combined structure was homogenous or heterogeneous, and this remains an unanswered question. 


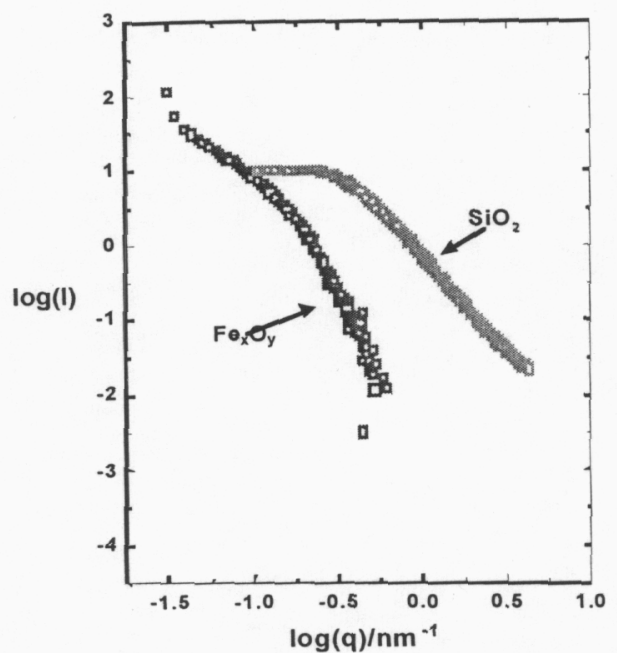

Figure 2. Phase contrast $\mathrm{SANS}\left(\mathrm{SIO}_{2}\right.$ matched $)$ shows similar structure for each phase with the primary particles slightly larger for the iron oxide component.

We qualitatively tested the thermite nanocomposites performance by initiation of the thermite reactions with a propane torch. Once ignited, the reaction proceeded such that the heat generated in the locally ignited region subsequently triggered the reaction in the adjacent reaction area, so that the reaction zone moved in the form of a wave until all the reactants were consumed. As can be seen in Fig. 3, the iron-oxide skeleton burned white hot without the evolution of smoke. While the binary iron-oxide silicate skeleton self-propagated, the combustion rate was noticeably slower and smoke rose from the burning nanocomposite. Since the tests were performed on xero-gelled composites that were not subjected to washing, the source of the smoke presumably was from incomplete combustion of organic materials residing within the pores.

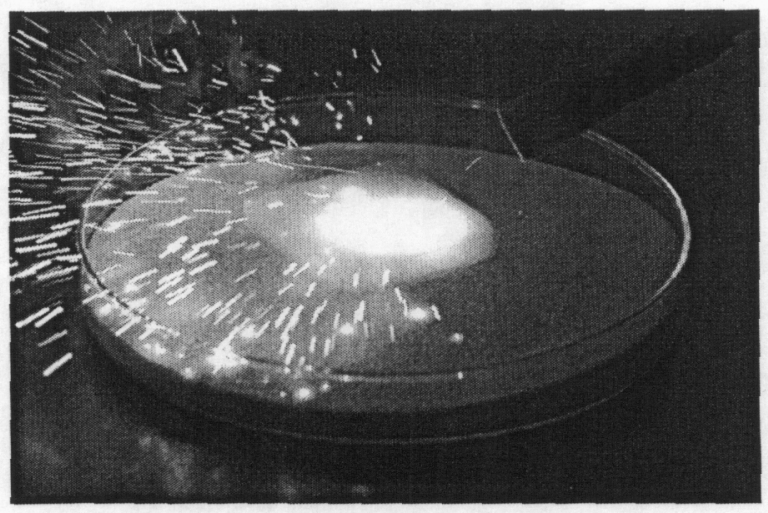

Figure 3. Thermitic reaction of a $\mathrm{Fe}_{x} \mathrm{O}_{y}-\mathrm{Al}$ energetic nanocomposite. The nanocomposite was place on a silica aerogel tile and ignited with a propane torch. 


\section{Discussion}

It is well known, for a given bulk density, that decreasing the reactant particle size increases the combustion rate [18-20], and this was one of our primary motivations for using sol-gel methodologies. Numerous experimental studies have elucidated the factors affecting the combustion rate for thermite systems. These factors include the particle size of reactants [18-20], pre-combustion compact density [20], addition of inert diluents $[8,9,18]$, and salt addition [19]. All microstructural analysis; HRTEM, SANS, and BET, indicated the oxidizer skeleton - fuel sol-gel derived materials were indeed nanocomposites. Clearly, the HRTEM results given here show smaller, more intimately dispersed reactants are possible with these approaches compared to the state-of-the-art mixing of sub-micron size powders approach.

The addition of inert diluents or salts of alkaline earth metals to thermite mixtures has also been shown to alter the combustion rate. Inert diluents, because of the production of less heat and the longer transport distance between reactants, decrease the combustion rate $[9,18]$. We observed this effect in our binary (iron oxide-silicate) oxidizing skeleton - Aluminum nanocomposites, where the combustion wave was noticeably slower than the iron oxide - Aluminum nanocomposites and gasless combustion was not attained.

The addition of a very small amount of an alkaline earth metal salt has been shown to dramatically increase the combustion rate. It has been proposed that the alkaline earth metal salt reacts with the oxide layer of the aluminum particles at a temperature lower than the ignition temperature of the thermite mixture, and consequently, the ignition temperature with salt addition is significantly reduced [19]. This addition could be easily accomplished with sol-gel methodologies, either dissolved into the sol or added as a particulate prior to gelation, and we are currently exploring these possibilities.

Dubrovin studied the effect of varying pre-combustion density and found the combustion rate decreases as bulk density increases reaching a minimum and then increases again [20]. He explained this behavior of the combustion rate to the effective thermal conductivity of the pressed mixture, which had been found to have similar bulk 
density dependence. It is interesting to note that Fricke observed a similar trend in thermal conductivity for silica aerogels [21], where the thermal conductivity decreased as the density to a minimum value, $\sim 120 \mathrm{~kg} / \mathrm{m}^{3}$, then increased as gaseous conduction predominated at ultralow densities. As such, it may be possible to use sol-gel methodologies to control gel density, and SCE to maintain porosity as an effective means for optimizing combustion rates.

The adiabatic temperature, a quantitative measure of the thermicity of the reaction, has also been extensively studied for a variety of thermitic compositions. Using the hydrated salt synthesis described here and/or classical metal alkoxide for silicon, we have shown that one can easily vary the composition of the oxidizing network. In principle, it should then be possible to use sol-gel chemistry to accurately control the adiabatic temperature over a large range, from $1800 \mathrm{~K}$ to greater than $4000 \mathrm{~K}$.

In addition to fine microstructural and compositional control, sol-gel methodology offers other advantages of safety and stability in energetic material processing. For example, ambient temperature gelation and low temperature drying schemes prevent degradation, and the water-like viscosity of the sol before gelation, allows easy casting to near-net-shapes, which is preferred over the hazardous machining alternative. The commercial production of thermites, mixing and pressing sub-micron powders of iron oxide and aluminum, is particularly hazardous with a long history of accidental explosions $[22,23]$. Ignition of partially dried sol-gel derived thermites, which used protic solvents in the synthesis, flashed off the remaining solvent but failed to ignite the thermite reaction. Increased safety could be achieved by using an aqueous medium for the sol-gel reactions, as described in procedures we have previously reported [14].

\section{Conclusion}

Energetic nanocomposites, with controlled oxidizer-fuel balances on the nanometer scale, are easily and reproducibly prepared using sol-gel chemistries. Microstructural control, unattainable by state-of-the-art composite processing, and precise oxidizer-fuel balance, not possible with current monomolecular synthesis, are 
major advantages. Essentially, sol-gel methodologies are helping bridge the gap between these two approaches.

We have just begun to explore the possibilities and are convinced that a vast number of opportunities exist for using sol-gel methods. Great promise exists for preparing multi-component oxidizer and fuel phases without detracting and in some instances improving performance. This may lead to tailored power output in sol-gel derived energetic composites.

\section{Acknowledgements}

This work is really the combined effort of a large number of research groups. The authors would like to thank Drs. John Holzrichter and Rokaya Al-Ayat for their enthusiastic support in backing this project. Other contributors from the Lawrence Livermore National Laboratory include: Mr. Mark Wall for the TEM anaylsis, Mr. Randy Weese for the thermal analyses, Ms. Suzy Hulsey for the BET analysis. Dr. Joe Satcher provided assistance in the preparation of this manuscript. Dr. Joe Martin, formerly of the Los Alamos National Laboratory, provided the nanometer scale aluminum. Dr. Celia Merzbacher and her group at the Naval Research Laboratory for the SANS measurements and helpful interpretations of the results. Finally, we would like to thank Dr. Gudrun Reichenauer, of the University of Wurzburg provided helpful discussions on all the results.

\section{References}

1 T.M. Tillotson, L.W. Hrubesh, R.L. Simpson, R.S. Lee, R.W. Swansiger and L.R. Simpson, J. Non Crystalline Solids 225, 358 (1998).

2 R.L. Simpson, T.M. Tillotson, L.W. Hrubesh, A. E. Gash, Proccedings Institut Chemische Energetic Materials Analysis, Diagnostic, and Testing Meeting, Karlsruhe, Germany, June 27-30, 2000.

3 A.J. Key, Aust. Weld. J. Autumn, 15 (1985).

4 Z.A. Munir and U. Anselmi-Tamburini, Mater. Sci. Repts 3, 277 (1989).

5 J.D. Walton Jr and N.E. Poulos, J. Amer. Ceram. Soc. 42, 40 (1959). 
6 G.B. Schaffer and P.G. McCormick, Appl. Phys. Lett. 55, 45 (1989).

7 A.G. Strunina, T.M. Martemyanova, V.V. Barzykin and V.I. Ermakov, Combust. Explos. Shock Waves (Engl. Transl.) 10, 449 (1974).

8 S.V. Kostin, A.G. Strunina and V.V. Barzykin, Combust. Explos. Shock Waves (Engl. Transl.) 18, 524 (1982).

9 E.I. Maksimov, A.G. Merzhanov and V.M. Shkior, , Combust. Explos. Shock Waves (Engl. Transl.) 2, 15 (1965).

10 M.L. Spector, E. Surani and G.L. Stukenbrocker, Ind. Eng. Chem. Process Des. Dev. 7, 117 (1968).

11 J.H. McLain, "Pyrotechnics: From the Viewpoint of Solid State Chemistry" (The Franklin Press, Philadelphia, PA, 1980).

12 A.C. Munger, J.H. Mohler and M.D. Kelly, in "Proceedings of the VIII International Pyrotechnics Seminar", 496 (IIT Research Institute, Chicago, IL,1982).

13 T.M. Tillotson, W.E. Sunderland, I.M. Thomas and L.W. Hrubesh, "Synthesis of Lanthanide and Lanthanide-Silicate Aerogels," J. of Sol-Gel Science and Technology 1, 241 (1994).

14 A. E. Gash, T. M. Tillotson, J. H. Satcher, Jr., J. F. Poco, L. W. Hrubesh, R. L. Simpson, Chemistry of Materials, manuscript submitted.

15 T.M. Tillotson and L.W. Hrubesh, J. Non-Crystalline Solids 145, 44 (1992).

16 C.J. Merzbacher, J.G. Barker, K.E. Swider, J.V. Ryan, R.A. Bernstein, D.R. Rolison, Journal of Non-Crystalline Solids, 225 (1995) 234.

17 Merzbacher et al, ACS symposium, Anaheim, CA, (Mar. 21-24, 1999), in press.

18 E.A. Balakir, Yu. G. Bushuev, N.A. Bareskov, A.E. Kosyakin, Yu. V. Kudryavtsev and O.N. Fedorova, Combust. Explos. Shock Waves (Engl. Transl.) 11, 36 (1975).

19 A.S. Dubrovin, V.L. Kuznetsov, V.I. Ezikov, N.A. Chirkov and L.N. Rusakov, Russ. Metall 5, 56 (1968).

20 A.S. Dubrovin, L.V. Slepova and V.L. Kuznetsov, Combust. Explos. Shock Waves (Engl. Transl.) 6, 60 (1970).

21 Fricke

22 N. Gibson, F.C. Lloyd and G.R. Perry, Inst. Chem. Eng. Symp. Ser. 25, 26 (1968).

23 K. Banizs, S. Szabo and J. Papp, Magy. Alum. 22, 319 (1985). 